\title{
Vibrational and surface-enhanced Raman spectra of vanillic acid
}

\author{
E. Clavijo, ${ }^{1}$ J. R. Menéndez ${ }^{2}$ and R. Aroca ${ }^{1 *} \dagger$ \\ ${ }^{1}$ Facultad de Ciencias, Universidad de Chile, Casilla 653 Santiago, Chile \\ ${ }^{2}$ Department of Physics, E.P.S. Ingeniería de Gijón, Universidad de Oviedo, Campus de Viesques, 33203, Gijón (Asturias), Spain
}

\begin{abstract}
The 3-methoxy-4-hydroxybenzoic acid or vanillic acid (VA) is a naturally occurring molecule important in winemaking. The spectral fingerprints of VA observed in the infrared and Raman spectra are assigned to fundamental vibrational wavenumbers supported by quantum chemical computations. The surfaceenhanced Raman scattering (SERS) of the VA has been obtained in silver colloidal solutions making possible analytical applications for detection of VA at picomole concentrations. Copyright $\odot 2008$ John Wiley \& Sons, Ltd.
\end{abstract}

KEYWORDS: absorption infrared spectroscopy; chemisorptions; surface-enhanced Raman scattering; vanillic acid

\section{INTRODUCTION}

Vanillic acid (VA) is a naturally occurring organic acid that has been isolated and characterized in rice, ${ }^{1}$ as an end product of metabolic processes, ${ }^{2}$ wine making ${ }^{3}$ among many other natural sources of VA. There are several reports on the separation of phenolic acids (including VA) and partial identification using Fourier transform infrared (FTIR) spectroscopy. ${ }^{4}$ VA has also been included as one of the phenolic acids tested in Fourier transform surface-enhanced Raman scattering (FT-SERS) studies. ${ }^{5}$ However, a detailed study of the vibrational fingerprints of VA is not available, and it is a necessary first step for its identification and development of a protocol for sensitive chemical analysis. The purpose of this work is to provide the vibrational infrared and Raman spectra to identify the fingerprints of VA, and show the results of surface-enhanced Raman scattering (SERS) ${ }^{6}$ on silver colloids.

\section{EXPERIMENTAL}

Analytical grade VA and silver nitrate were obtained from Sigma Aldrich and used without further purification. Raman spectra of the pure VA solid were obtained directly from the powder, while IR spectra were recorded from the powder dispersed in $\mathrm{KBr}$ pellets. All Raman spectra were collected

\footnotetext{
*Correspondence to: R. Aroca, Facultad de Ciencias, Universidad de Chile, Casilla 653 Santiago, Chile. E-mail: raroca1@cogeco.ca ${ }^{\dagger}$ Permanent address: Materials and Surface Science Group, Faculty of Science, University of Windsor, Windsor, Canada.
}

with a Renishaw research Ramanscope 1000, or a Renishaw in Via Raman microscope, both equipped with Peltier-cooled CCD detectors $\left(-70{ }^{\circ} \mathrm{C}\right)$, and Leica microscopes. The spectrographs use $1800 \mathrm{~g} / \mathrm{mm}$ gratings with additional band-pass filter optics. Excitation lines of 442, 514.5, and $632.8 \mathrm{~nm}$ were used, and did not reveal any significant dispersion in relative intensities. SERS spectra in solution were recorded using the macro attachment and a $15 \times$ objective. All infrared absorption measurements were recorded with a Perkin Elmer FTIR spectrometer, System 2000, employing a DTGS detector. Each spectrum was measured with 300 scans, and $4 \mathrm{~cm}^{-1}$ resolution. Citrate and borohydride ${ }^{7}$ colloidal silver was prepared according to the procedure given in Ref. 6 pp. 144-146. The colloidal Ag was used as prepared without further dilution or aggregation with salts.

\section{Computational methods}

All reported calculations have been performed using the Gaussian 98 (Revision A.3) suite of programs, ${ }^{8}$ and employed Becke's three parameter functional including the correlational functional of Lee et al., ${ }^{9}$ B3LYP. In order to calculate an optimized structure and vibrational spectra for VA, the 6-311G(d,p) basis set was employed using tight convergence criteria. All peaks in the presented calculated Raman and infrared spectra were scaled with a 0.9669 scaling factor, ${ }^{10}$ and artificially given a $7 \mathrm{~cm}^{-1}$ full width at half maximum. The calculated spectra (harmonic approximation for an isolated molecule) are to be seen as a guide to the assignment of vibrational modes where large differences between observed and calculated values should be expected since the experimental spectra 
correspond to solid samples with strong hydrogen bond interactions.

\section{RESULTS AND DISCUSSION}

\section{Infrared and Raman spectra}

There are 54 fundamental vibrational modes in 3-methoxy-4hydroxy benzoic acid. The molecule has a $C_{1}$ symmetry point group and the calculated dipole moment is 4.07 debye. The high wavenumber region contains characteristic wavenumbers of the $\mathrm{OH}$ stretchings that are observed in one broad band in the IR (Fig. 1) and also in the Raman spectrum, where a deconvolution provides two overlapping bands at 3487 and $3476 \mathrm{~cm}^{-1}$. The observed $\mathrm{OH}$ wavenumbers are much lower than the calculated ones (3699 and $3649 \mathrm{~cm}^{-1}$ ) due to hydrogen bonding. The observation of close $\mathrm{OH}$-stretching bands is similar to previous findings for salicylic acid. ${ }^{11}$ The $\mathrm{CH}$-stretching region encompasses six $\mathrm{CH}$ stretching; three from the aromatic ring and three from the $\mathrm{CH}_{3}$ moiety. The Raman spectra and the corresponding calculated spectra are shown in Fig. 2. In the high wavenumber region of the spectra, the anharmonicity along can explain substantial differences between calculated and observed wavenumbers. Although in the calculated spectrum only four wavenumbers have high relative intensity, in the experimental spectrum, all the six $\mathrm{CHs}$ are observed. The Raman spectra of VA cannot be detected in the dilute water solutions $\left(10^{-3} \mathrm{M}\right)$; but it can be seen from a saturated solution and long integration times. Notably the observed Raman scattering of the saturated solution at $514.5 \mathrm{~nm}$ is identical with the Raman scattering at $442 \mathrm{~nm}$ excitation and they are shown in Fig. 3. The vibrational wavenumbers, intensities, and assignments are given in Table 1 . In the infrared spectrum, the $\mathrm{CH}$ are observed with relatively weak intensity. The infrared spectrum shown in Fig. 1 is in full agreement with the FTIR spectrum given as part of a comprehensive study on the spectroscopy and photophysics of VA acid in different solvents, ${ }^{12}$ and also with the spectral region between 1000-1800 $\mathrm{cm}^{-1}$ shown in Ref. 13.

The carbonyl stretching is calculated at $1739 \mathrm{~cm}^{-1}$; but due to hydrogen bonding is observed at $1680 \mathrm{~cm}^{-1}$ in the FTIR spectrum, as can be seen in Fig. 1. The same red shift was seen in salycilic acid. ${ }^{11}$ The $\mathrm{C}=\mathrm{O}$ is not a characteristic vibration in the Raman spectrum. The ring stretching vibration at $1601 \mathrm{~cm}^{-1}$ is the most intense band in the Raman spectra as can be seen in Fig. 3. Ring-stretching modes and $\mathrm{CH}$ bending dominate the $1500-1000 \mathrm{~cm}^{-1}$ region of the Raman spectrum. Vibrational modes in the low wavenumber region of the spectrum contain contributions of several internal coordinates and their assignment is a reduction approximation to one of two of the internal coordinates.

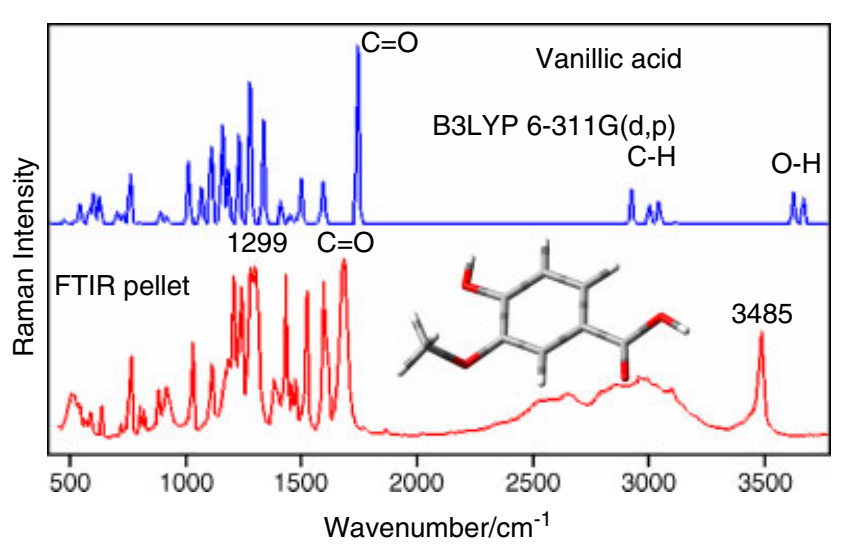

Figure 1. Calculated and experimental infrared spectra of VA in a $\mathrm{KBr}$ pellet. This figure is available in colour online at www.interscience.wiley.com/journal/jrs.

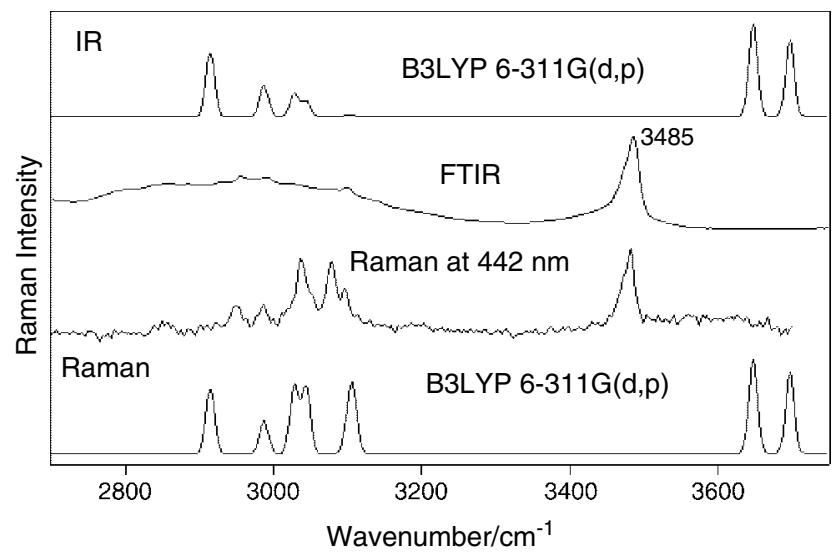

Figure 2. High wavenumber region of the Raman and infrared spectra of VA and the corresponding calculated wavenumbers.

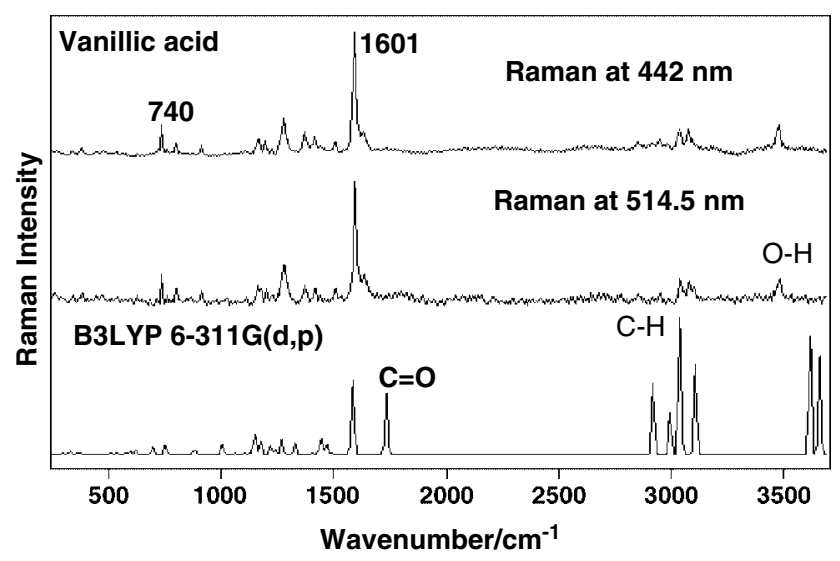

Figure 3. Raman scattering of solid VA excited at $442 \mathrm{~nm}$, and that of a saturated VA solution excited at $514.5 \mathrm{~nm}$. The bottom traces are the calculated spectrum. 
Table 1. Calculated and observed fundamental vibrational wavenumbers of vanillic acid

\begin{tabular}{|c|c|c|c|c|c|}
\hline $\begin{array}{l}\text { Calculated } \\
\mathrm{cm}^{-1}\end{array}$ & $\begin{array}{l}\text { Infrared } \\
\mathrm{Km} / \mathrm{mol}\end{array}$ & $\begin{array}{l}\text { Raman } \\
\AA^{4} / \mathrm{amu}\end{array}$ & $\begin{array}{c}\text { Raman } \\
\text { Observed }\end{array}$ & $\begin{array}{c}\text { Infrared } \\
\text { Observed }\end{array}$ & Assignment \\
\hline 62 & 1.6 & 0.3 & & & $\mathrm{COOH}$ twisting \\
\hline 67 & 3.2 & 1.0 & & & Torsion \\
\hline 110 & 0.2 & 0.6 & & & Ring wagging \\
\hline 141 & 2.3 & 2.5 & & & $\mathrm{CH}_{3}$ torsion \\
\hline 155 & 1.2 & 1.1 & & & Skeletal rocking \\
\hline 191 & 0.5 & 0.5 & $205(6)$ & & $\mathrm{COOH}$ rocking \\
\hline 260 & 1.5 & 1.0 & $276(4)$ & & Ring twisting \\
\hline 300 & 2.6 & 1.6 & & & $\mathrm{COH}$ rocking $\mathrm{n}$ \\
\hline 333 & 10.6 & 3.9 & & & Ring deformation \\
\hline 347 & 67.7 & 2.3 & $343(14)$ & & $\mathrm{OH}$ wagging \\
\hline 360 & 27.1 & 1.5 & & & Ring twisting \\
\hline 393 & 6.5 & 1.0 & $383(15)$ & & Ring deformation \\
\hline 474 & 7.0 & 1.1 & $450(6)$ & & Ring wagging \\
\hline 517 & 10.8 & 2.8 & $482(7)$ & & Ring deformation \\
\hline 534 & 40.8 & 3.1 & $543(7)$ & $541 \mathrm{~m}$ & Ring deformation \\
\hline 577 & 29.0 & 2.5 & $566(2)$ & $565 \mathrm{w}$ & $\mathrm{CO}$ rocking \\
\hline 600 & 59.4 & 4.6 & & $589 \mathrm{~m}$ & scissors $(\mathrm{COOH})$ \\
\hline 612 & 31.0 & 3.7 & $635(12)$ & $640 \mathrm{~m}$ & Ring deformation \\
\hline 700 & 20.6 & 10.7 & $722(6)$ & $722 \mathrm{w}$ & Ring deformation \\
\hline 721 & 13.1 & 1.0 & $740(55)$ & & Ring twisting \\
\hline 752 & 69.7 & 1.4 & & $758 \mathrm{~s}$ & $\mathrm{CH}$ wagging \\
\hline 757 & 23.4 & 12.7 & $765(8)$ & $766 \mathrm{~s}$ & Ring breathing \\
\hline 796 & 3.3 & 0.4 & $807(24)$ & $806 \mathrm{~m}$ & $\mathrm{CH}$ twisting \\
\hline 886 & 22.3 & 6.7 & & & $\mathrm{COCH}_{3}$ stretch \\
\hline 909 & 8.7 & 0.8 & $917(19)$ & $918 \mathrm{~m}$ & $\mathrm{CH}$ wagging \\
\hline 921 & 4.4 & 0.5 & $929(6)$ & & $\mathrm{CH}$ twisting \\
\hline 1005 & 119.9 & 14.9 & & & $\mathrm{OCH}_{3}$ stretch \\
\hline 1060 & 75.6 & 1.5 & $1030(8)$ & $1029 \mathrm{~s}$ & $\mathrm{CH}$ bend + ring st. \\
\hline 1101 & 159.6 & 3.0 & & & $\mathrm{CH}$ bending \\
\hline 1133 & 9.2 & 4.6 & & $1113 \mathrm{~s}$ & $\mathrm{CH}_{3}$ deformation \\
\hline 1144 & 134.7 & 24.5 & $1118(6)$ & & $\mathrm{CO}$ stretch $(\mathrm{COOH})$ \\
\hline 1149 & 51.9 & 5.3 & $1167(21)$ & $1169 \mathrm{~m}$ & $\mathrm{CH}$ bending \\
\hline 1170 & 86.7 & 15.7 & $1181(22)$ & $1187 \mathrm{~m}$ & $\mathrm{CH}_{3}$ deformation \\
\hline 1221 & 156.9 & 12.8 & $1205(20)$ & 1205 s & $\mathrm{CO}\left(\mathrm{CH}_{3}\right)$ stretch \\
\hline 1242 & 3.9 & 4.2 & $1235(6)$ & $1240 \mathrm{~s}$ & $\mathrm{CH}$ bending \\
\hline 1272 & 263.3 & 22.9 & $1286(40)$ & 1282 vs & $\mathrm{COH}+\mathrm{CO}\left(\mathrm{CH}_{3}\right)$ st. \\
\hline 1327 & 216.0 & 21.0 & 1299 (19) & 1299 vs & $\mathrm{OH}$ bending \\
\hline 1329 & 0.1 & 0.3 & & & $\mathrm{OH}$ bend + ring st. \\
\hline 1404 & 45.2 & 3.2 & $1379(14)$ & $1378 \mathrm{~m}$ & $\mathrm{CH}_{3}$ bend + ring st. \\
\hline 1437 & 21.7 & 15.1 & $1426(14)$ & & Ring stretch $+\mathrm{CH}_{3}$ bend \\
\hline 1438 & 8.4 & 14.1 & & $1435 \mathrm{~s}$ & $\mathrm{CH}_{3}$ bend + ring st. \\
\hline 1460 & 7.7 & 13.1 & & $1457 \mathrm{~m}$ & $\mathrm{CH}_{3}$ bending \\
\hline 1491 & 93.4 & 1.4 & & $1475 \mathrm{~m}$ & Ring stretch \\
\hline 1574 & 15.3 & 8.0 & $1520(9)$ & $1525 \mathrm{~s}$ & Ring stretch \\
\hline 1590 & 85.5 & 110.3 & $1601(100)$ & $1600 \mathrm{~s}$ & Ring stretch \\
\hline 1739 & 344.8 & 91.5 & & 1680 vs & $\mathrm{C}=\mathrm{O}$ stretch \\
\hline 2915 & 64.1 & 114.6 & $2854(2)$ & 2857 vw & $\mathrm{CH}$ stretch $\left(\mathrm{CH}_{3}\right)$ \\
\hline 2988 & 32.3 & 58.8 & $2953(4)$ & 2954 w & $\mathrm{CH}$ stretch $\left(\mathrm{CH}_{3}\right)$ \\
\hline
\end{tabular}


Table 1. (Continued)

$\begin{array}{lrrccc}\begin{array}{l}\text { Calculated } \\ \mathrm{cm}^{-1}\end{array} & \begin{array}{c}\text { Infrared } \\ \mathrm{Km} / \mathrm{mol}\end{array} & \begin{array}{c}\text { Raman } \\ \AA^{4} / \mathrm{amu}\end{array} & \begin{array}{c}\text { Raman } \\ \text { Observed }\end{array} & \begin{array}{c}\text { Infrared } \\ \text { Observed }\end{array} & \text { Assignment } \\ 3029 & 24.0 & 120.2 & 2988(3) & 2989 \mathrm{w} & \mathrm{CH} \text { stretch }\left(\mathrm{CH}_{3}\right) \\ 3045 & 16.0 & 116.8 & 3038(9) & & \text { CH ring stretch } \\ 3103 & 2.1 & 54.1 & 3080(8) & & \text { CH ring stretch } \\ 3109 & 0.7 & 89.4 & 3097(4) & 3098 \mathrm{w} & \text { CH ring stretch } \\ 3649 & 93.0 & 165.5 & 3476(4) & & \text { OH stretching }(\mathrm{COOH}) \\ 3699 & 77.3 & 143.5 & 3487(5) & 3485 \mathrm{~s} & \text { OH stretching }\end{array}$

Relative intensities for Raman are given in parenthesis.

Infrared: vs, very strong; s, strong; m, medium; w, weak and vw, very weak.

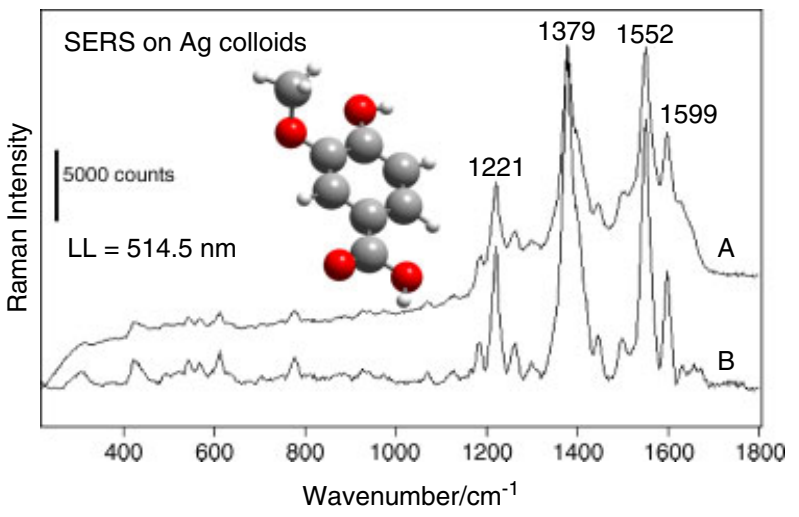

Figure 4. SERS spectrum of VA on Ag colloids. (A) Raw spectrum and $(B)$ baseline corrected spectrum excited with the $514.5 \mathrm{~nm}$ laser line. This figure is available in colour online at www.interscience.wiley.com/journal/jrs.

\section{Surface-enhanced Raman scattering}

Reproducible and stable SERS spectra of VA were obtained in both the citrate and borohydride sols. The results for borohydride colloids obtained using the macro attachment and $15 \times$ objective are shown in Fig. 4 . The raw spectrum carries the ubiquitous background observed in the SERS spectra, ${ }^{14}$ and the baseline corrected spectrum is also shown in Fig. 4. The stock solution of VA was $10^{-3}$ M. $300 \mu$ of the solution were added to $3 \mathrm{ml}$ of the colloidal solution as prepared $(\mathrm{pH}$ ca 7.3). The incident excitation line was the $514.5 \mathrm{~nm}$ of the argon-ion laser. Under identical conditions no Raman signal could be detected from the stock solution. The same SERS spectrum shown in Fig. 4 was also obtained from cast colloidal solution, containing VA, on glass. The SERS spectra are quite different from that of the solid VA presented in Fig. 3. These differences in relative intensities and wavenumbers can only be explained in terms of chemical adsorption of the VA to the silver surface. A close examination reveals that the characteristic vibration of the $\mathrm{COO}^{-}$moiety at $1379 \mathrm{~cm}^{-1}$ is the most intense band in the spectrum. ${ }^{15}$ Therefore it is reasonable to conclude that VA is chemically adsorbed forming a complex through the carboxylic group. There are four main characteristic bands in the SERS spectrum: the symmetric $\mathrm{COO}^{-}$stretching at $1379 \mathrm{~cm}^{-1}$, the antisymmetric $\mathrm{COO}^{-}$ stretching at $1552 \mathrm{~cm}^{-1}$, the ring stretching at $1599 \mathrm{~cm}^{-1}$ and the $\mathrm{CH}$ bending at $1221 \mathrm{~cm}^{-1}$.

In an early report ${ }^{5}$ on Fourier transform SERS (FT-SERS) of VA on Ag colloids (at $\mathrm{pH}=4.1$ ) excited at $1064 \mathrm{~nm}$ was also found that the VA was chemisorbed and the COO stretching mode was the most intense band in the observed SERS spectrum. Since the spectrum shown in Fig. 4 is reproducible under several conditions (in liquid, cast on glass), we assigned the observation to the chemisorbed species of VA. When photodissociation (burning) of the sample is caused by high energy density on the sample under the microscope, the typical carbon spectra are recorded. From the SERS spectra obtained from cast colloids, it can be estimated that picomole quantities of VA may be detected by SERS on colloidal silver. The group of phenolic acids related to VA is the $p$-hydroxybenzoic acid, the gallic and the syringic acids. The SERS of $p$-hydroxybenzoic acid is also due to chemisorbed species showing the strong symmetric COO stretching mode. ${ }^{16}$ However, there are some subtle differences with the results shown here for VA. These phenolic acids are easily photodissociated on the Ag surface and their SERS is elusive. Finding the appropriate SERS substrate that may allow their identification in mixtures is the next step in this work.

\section{CONCLUSIONS}

SERS spectra of VA, a phenolic acid, in the visible $(514.5 \mathrm{~nm})$ are reported here for the first time. The infrared and Raman spectra of VA have been revisited and assigned.

\section{Acknowledgements}

Financial assistance from Fondecyt 1070078 is gratefully acknowledged.

\section{REFERENCES}

1. Kuwatsuka S, Oshima Y. Nippon NogeiKagaku Kaishi 1961; 35: 67.

2. Dirscherl W, Thomas H, Schriefers H. Acta Endocrinol. 1962; 39: 385. 
3. Nose A, Hamasaki T, Hojo M, Kato R, Uehara K, Ueda T. J. Agric. Food Chem. 2005; 53: 7074.

4. Melhuish JH, Willis RB, Wright CS Jr. J. Chem. Ecol. 1987; 13: 317.

5. Sanchez-Cortes S, Garcia-Ramos JV. J. Colloid Interface Sci. 2000; 231: 98.

6. Aroca R. Surface-Enhanced Vibrational Spectroscopy. John Wiley \& Sons: Chichester, 2006

7. Lee PC, Meisel D. J. Phys. Chem. 1982; 86: 3391.

8. Frisch MJ, Trucks GW, Schlegel HB, Scuseria GE, Robb MA, Cheeseman JR, Zakrzewski VG, Montgomery JJA, Stratmann RE, Burant JC, Dapprich S, Millam JM, Daniels AD, Kudin KN, Strain MC, Farkas O, Tomasi J, Barone V, Cossi M, Cammi R, Mennucci B, Pomelli C, Adamo C, Clifford S, Ochterski J, Petersson GA, Ayala PY, Cui Q, Morokuma K, Malick DK, Rabuck AD, Raghavachari K, Foresman JB, Cioslowski J, Ortiz JV, Stefanov BB, Liu G, Liashenko A, Piskorz P, Komaromi I, Gomperts R, Martin RL, Fox DJ,
Keith T, Al-Laham MA, Peng CY, Nanayakkara A, Gonzalez C, Challacombe M, Gill PMW, Johnson B, Chen W, Wong MW, Andres JL, Gonzalez C, Head-Gordon M, Replogle ES, Pople JA. Gaussian: Pittsburgh, 1998.

9. Lee C, Yang W, Parr RG. Phys. Rev. B 1988; 37: 785.

10. Irikura KK, Johnson RD, Kacker RN III. J. Phys. Chem. A 2005; 109: 8430

11. Goulet PJG, Aroca RF. Can. J. Chem. 2004; 82: 987.

12. Stalin T, Rajendiran N. J. Mol. Struct. 2006; 794: 35.

13. Surowiec I, Baena JR, Frank J, Laurell T, Nilsson J, Trojanowicz M, Lendl B. J. Chromatogr. A 2005; 1080: 132.

14. Itoh $\mathrm{T}$, Biju $\mathrm{V}$, Ishikawa $\mathrm{M}$, Kikkawa $\mathrm{Y}$, Hashimoto $\mathrm{K}$, Ikehata $\mathrm{A}$, Ozaki Y. J. Chem. Phys. 2006; 124: 134708/1-134708/6.

15. Wang L-R, Fang Y. Spectrochim. Acta, Part A 2006; 63: 614.

16. Zhang J-B, Fang Y. Colloids Surf., A: Physicochem. Eng. Aspects 2005; 266: 38. 